\title{
Writing Philosophy from the Periphery: Lixing as Foundational Empty Signifier in Tang Junyi's Cultural Consciousness and Moral Reason
}

\author{
Philippe Major ${ }^{1}$ \\ Published online: 6 October 2020 \\ (C) The Author(s) 2020, corrected publication 2020
}

\begin{abstract}
This article adopts Ernesto Laclau's notion of empty signifier to discuss Tang Junyi's uses of the concept of lixing ('reason' or 'rationality') in his seminal work Cultural Consciousness and Moral Reason (文化意識與道德理性; 1958). My dual goal, in doing so, is to bring to light the relations of power constitutive of the text's discourse on lixing and relate them to the problematic of writing philosophy from the periphery. I argue that in this work, lixing's dual referents - as a translation of 'reason' and as denoting a Neo-Confucian faculty to intuit moral truths - allow Tang to inscribe himself in a philosophical field designed to exclude non-Western philosophies, while at the same time enabling him to symbolically relegate Euro-American philosophy to a peripheral position by filling in the notion of lixing with a content that legitimizes his own agenda. Tang could thus authorize his Confucian metaphysics by presenting it as the true content of lixing, understood not only as a universal faculty enabling humanity's access to all that is universal, but also as a condition sine qua non of for one's inclusion in the philosophical game. By attempting to co-opt the empty signifier (lixing/reason) for his own purposes, I argue Tang employs one of two possible strategies that can be adopted by those situated at the periphery in order to oppose the hegemon; one that leaves the structure of power relations intact but working in favor of the periphery.
\end{abstract}

Keywords Tang Junyi · Empty signifier · New Confucianism • Chinese philosophy · Periphery $\cdot$ Hegemony

Philippe Major

philippe.major@unibas.ch

1 Institute for European Global Studies, University of Basel, Basel, Switzerland 
The lack of space afforded to non-Western philosophical traditions in EuroAmerican institutions of higher learning has recently been the topic of an important controversy in the field of philosophy. ${ }^{1}$ One of the many virtues of the debate has been its ability to highlight that philosophy takes place, as a discipline, within social relations of power from which it is not entirely autonomous. However, much remains to be done in order to better understand the relationship philosophy entertains with such relations of power, especially as it pertains to philosophical games of inclusion and exclusion which often tend to reproduce the existing socio-economic as well as geo-political relations of power in place.

In this essay, I regard the idea of absolute autonomy as a fiction constitutive of the field of philosophy, and suggest that its fictional nature might be more conspicuous in works that were written outside the hegemonic centers of knowledge production, in a peripheral condition that asks of philosophical texts that they continuously justify and legitimize their very existence along with the claims they make. ${ }^{2}$ (By comparison, an Anglo-Saxon philosophical text simply needs to justify its assertions through argumentation, without the need to argue for the legitimacy of the Anglo-Saxon tradition of philosophizing.) That Chinese philosophy constantly needs to be legitimized by its practitioners and advocates - although this need is felt less strongly over time, it is still very much present today-might be understood as a by-product of the postcolonial relations of power that hegemonize Euro-American philosophical production. But precisely because of this need to justify itself in relation to Euro-American philosophy, the reader of a Chinese philosophical text often tends to be reminded of the socio-political nature of what is being read, and thus of the text's supposed 'lack' of autonomy, or even of its 'failure' to adopt an objective, detached gaze. ${ }^{3}$ In short, by being forced to continuously justify its existence within actual socio-historical relations of power, non-Western philosophy loses (but more readily sees through) the very autonomy which is regarded as the condition sine qua non for one's inclusion in philosophy's exclusive club.

\footnotetext{
${ }^{1}$ The debate was sparked by a New York Times article published in 2016 (Garfield and Van Norden 2016), in which Jay Garfield and Bryan W. Van Norden suggest that Philosophy Departments which exclude such traditions should be renamed to make explicit the fact that their focus remains narrowly centered on Western Philosophy. On this topic, see also Van Norden 2017; Bruya 2017; and Defoort 2017.

${ }^{2}$ On the topic of the legitimacy of Chinese philosophy, see Defoort 2001, 2006; and Defoort and Ge 2005. In French, see Cheng 2005.

${ }^{3}$ While the explicit conceptualization of philosophy as a practice that revolves around a 'view from nowhere' is by no means widespread today, certain philosophical practices - such as the rejection of Indian, African, or Chinese philosophies as topics worth discussing in philosophy departments - suggest it might still inform the philosophical doxa in the Euro-American region.
} 
It is precisely this game of inclusion and exclusion which is the central object of the present study. ${ }^{4}$ I wish to argue that one of the most important means through which modern Confucian texts simultaneously attempt to inscribe themselves in a philosophical field which is designed to exclude them while at the same time symbolically relegating Euro-American philosophy to a peripheral position is by redefining key concepts of modern Euro-American philosophy. This is done in order not only to sinicize such concepts, but also to delimitate their meaning in order to serve the particular purposes of the author (against competing projects within and outside the Chinese-speaking world). This strategy allows New Confucian texts to avoid having to plead for their inclusion in the club of philosophy explicitly, and enables them to present themselves as already playing the philosophical game with the authoritative tools of the hegemon, which they employ in a manner that is meant to legitimize their personal agenda. This is the case, I argue, of Tang Junyi's (唐君毅; 1909-1978) use of lixing (理性; usually translated from and into 'rationality' or 'reason') in his seminal work Cultural Consciousness and Moral Reason (文化意識與道德理性; 1958).

By looking at Tang's conception of lixing through the lens of Laclau's notion of empty signifier, my dual goal is to bring to light the relations of power constitutive of the text's discourse on lixing and relate them to the problematic of writing philosophy from the periphery. I wish to point out how Tang on the one hand reproduces, in his understanding of lixing, the structural role played by rationality in Euro-American philosophy - that of providing its bearer with autonomy and universality - while on the other hand redefining in a Neo-Confucian manner the functioning of lixing as an intuitive grasp of a metaphysical source of morality. In the process, Tang could authorize his Confucian metaphysics by presenting it as the true content of lixing, understood not only as a universal faculty enabling humanity's access to all that is universal, but also as a notion regarded as so central to philosophy's enterprise that one could simply not avoid or reject it without risking to compromise one's project.

My goal, in doing so, is not to reduce philosophy to a mere politics of hegemonyproduction. Rather, I wish to highlight the complex ways in which philosophy's claim to autonomy often hides relations of power, shaped around a hegemonic center, that do not exhaust the philosophical field but are certainly constitutive of it, so much so that those writing at the periphery feel compelled to make use of the tools of the hegemon in opposition to it. My point is not that a power-relation analysis provides us with the one key that unlocks the meaning of Tang's text. In fact, the direct object of my analysis in this essay is not so much Tang's text itself, but rather the complex and subtle relations of power that shape it along with Tang's construal of the notion of lixing. ${ }^{5}$ In other

\footnotetext{
${ }^{4}$ I borrow the expression "philosophical game" from Bourdieu 2000: 11, 28. For a discussion of exclusionary practices and discursive techniques employed by philosophers located at the center of knowledge production in order to enforce boundary marking and the 'walling out' of Asian philosophies, see Olberding 2017.

${ }^{5} \mathrm{I}$ am aware that aspects of the text become hidden when approached from such a perspective: certainly, the question of the text's inheritance of its discourse from the various sites of tradition and culture will not be addressed by such a methodological approach, as is the question of the intentions of the author.
} 
words, I wish to focus on the traces of power struggles that linger in Tang's text without assuming that such traces entail that the author built a philosophical system around a purposeful attempt at decentering the hegemon. ${ }^{6}$ It is my contention that such relations of power have been, throughout the twentieth century in China, an integral component of the philosophical uses of the notion of lixing; Tang's text provides one window through which we can observe and reflect on the complex functioning of such uses.

This highlights my engagement with the notion of the death of the author, understood as entailing that texts are the products not of ex nihilo creators, but of authors shaped by the socio-historical conditions within which they write as well as by the language of the texts that have overtly or unconsciously shaped them as authors. My emphasis on the socio-historical conditions that shape philosophical textuality, rather than on intertextuality, betrays my interest in developing a sociological understanding of philosophical textuality that takes place from within philosophy and that is deployed for philosophical aims. My aim in approaching the text in such a manner is also that of supplementing the secondary literature on New Confucianism and Tang Junyi, whose work has thus far been for the most part approached from the perspectives of Intellectual History, ${ }^{7}$ Philosophy, ${ }^{8}$ or Religious Studies. ${ }^{9}$

Before taking a closer look at the place Tang assigns to lixing in his philosophical edifice in Cultural Consciousness and Moral Reason, I first introduce Ernesto Laclau's notions of empty signifier and hegemony, which I believe help conceptualize the power dynamics at work in Tang's use of lixing, before reflecting shortly on the discursive techniques at the disposal of those philosophers situated at the periphery of the

\footnotetext{
${ }^{6}$ As such, I will not address the issue of whether the redefinition of lixing taking place in Cultural Consciousness and Moral Reason was consciously intended or not by Tang as a means to decenter the hegemon. To answer this question would require a broader inquiry into Tang's other works as well as his correspondence, his diaries, etc. What interests me here is to highlight power relations as they take place not at the level of the author, but at that of the text itself. For readers interested in the question of Tang's intentions, it is worth noting, however, that there are significant reasons to believe Tang remained highly aware of wider socio-political concerns, including the issue of hegemony and imperialism, while engaging in philosophy. For one thing, Tang presents philosophy, in Cultural Consciousness and Moral Reason, as having for goal the transformation of the socio-political order in the image of an ideal accessed through lixing. Philosophy, in Tang's view, is therefore not divorced from socio-political concerns, although, as we will see, the ideals discovered by philosophers through the faculty of lixing transcend the limitations of the current socio-political order. As such, while philosophy is not necessarily determined by the socio-political, it must serve a sociopolitical purpose: that of reshaping reality in the form of ideality. It is therefore highly possible Tang saw his philosophical output as contributing to the decentering of Euro-American knowledge production. As Thomas Fröhlich notes, 'Tang did not ignore particular historical conditions and intellectual traditions - such as those in China-which could shape modernity in different parts of the world. On the contrary, in reconsidering China's intellectual traditions in the broad sense, he fought against what he perceived to be manifestations of a 'Western' colonial hegemony or even cultural imperialism in the spheres of education, science, the liberal arts, and public debate' (Fröhlich 2017: 6). On Tang's concern with the issue of imperialism, see also Fröhlich 2017: 96-99.

${ }^{7}$ The only monograph devoted entirely to Tang in English is that of Thomas Fröhlich (2017), which provides a masterful analysis of Tang's thought, particularly his political thought, within the context of modernity and the state of exile in which Tang lived during his most productive years as a philosopher. Another analysis of Tang's thought is provided by Thomas Metzger (2005), although as Thomas Fröhlich notes in his monograph (p.25n3), Metzger does not discuss Cultural Consciousness and Moral Reason in this work.

${ }^{8}$ In English, see van den Stock 2016 and Ames 2010. In Chinese, the list of publications is too long to enumerate exhaustively here, but the recently published monograph of Huang Kuan-Min (2018) and the first systematic analysis of Tang's philosophy by Li Du (1982) are of particular interest. On Tang's philosophy of history, see also Huang 2010.

${ }^{9}$ In English, see Chiu 2016; Ng 1998. In Chinese, see Chen 2015.
} 
hegemonic center of knowledge production who wish to simultaneously insert themselves in the philosophical game as defined by the hegemon and reposition their periphery as center.

\section{Two Counterhegemonic Strategies}

In Emancipation(s), Ernesto Laclau introduces the notion of empty signifiers, which are those signifiers that point to the absent fullness of the social order. In a particularly chaotic society, for example, 'order' becomes an empty signifier representing that which the society aspires to; so much so that it can be expected that various factions will find interest in shaping the notion of order in a way that benefits them. In such a society, Laclau comments, "order" is present as that which is absent; it becomes an empty signifier, as the signifier of an absence. In this sense, various political forces can compete in their efforts to present their particular objectives as those which carry out the filling of the lack. To hegemonize something is exactly to carry out this filling function' (Laclau 1996: 44). Empty signifiers thus enable various groups to present their own agendas as universal, something which only the hegemonic group succeeds in doing, and only precariously so. It is precisely because the 'Universal is empty,' as Žižek notes, that it is 'as such always-already filled in, that is, hegemonized by some contingent, particular content that acts as its stand-in - in short, each Universal is the battleground on which the multitude of particular contents fight for hegemony' (Žižek 1999: $100-101) .^{10}$

The power struggles which characterize attempts to fill in the empty signifier with particular content might be more ostentatious when they take place within the political arena. In times of war, for instance, peace becomes an object of contention over which various opposing groups fight in order to ensure that their conceptualization of peace, and the complex hierarchical relations that comprise it, will be accepted as the only legitimate one. The pax americana of the Cold War, while presented as the only viable option in American discourse, was nonetheless always implicitly aimed at delegitimizing the pax sovietica - and vice versa, of course. Within this context, it is in one's advantage to present one's alternative as the only possible one; as the natural course events have to take, rather than should take. This is one of the means through which the particular can be universalized. While this is more evident with regard to discursive struggles that take place within the political arena, I suggest a similar dynamic takes place in philosophical discourse, although it is often unacknowledged to the extent that philosophical texts generally have advantage in presenting their claims as autonomous from struggles for hegemony.

\footnotetext{
${ }^{10}$ For Žižek, the absent fullness of the social order does not appear to be as central in his understanding of empty signifiers as it is for Laclau: any universal can become a battleground on which various factions fight for hegemony. I would tend to agree with him on this point, although I acknowledge that those empty signifiers that remind us of an absence in the social order are most likely to be singled out as particularly valuable symbolic commodities to have on one's side. Lixing is such a symbolic commodity, I would argue, since it has often been regarded, in modern China, as that which the Chinese socio-political order lacks; the goal of modernity, within such a reading, is to 'rationalize' or more properly lixinghua (理性化) the social order. We will see in a moment that Tang, although he redefines lixing in major ways, does not depart from this tendency to regard lixing as that which Chinese society — or any society for that matter-lacks.
} 
Philosophers working from within the centers of hegemonic power can in fact reach a significant amount of autonomy, although this very autonomy reiterates established relations of power. Those who are positioned outside these centers of power, however, must play a subtle game by which they attempt to symbolically reposition themselves in a central position while employing a form of discourse retaining, at least in appearance, a high level of autonomy from mundane questions of power and authority. One can therefore argue that Euro-American rationality should be rejected or perhaps relegated to a lower echelon of the human quest for truth and the good, but one has to do so for the right reasons: that is, simply because one has logically demonstrated that this is the case. In short, one has to answer to the criteria established by the Euro-American philosophical field whenever one wants to oppose it. This is reminiscent of Fabien Eboussi Boulaga's characterization of the predicament of non-Western philosophy in general, and African philosophy in particular:

Either one has to philosophise or one does not have to philosophise. If one has to philosophise, one has to do it in the Western mode (the pleonasm is not redundant). And if one does not have to philosophise in the Western mode, in order to demonstrate that one does not have to philosophise in the Western mode, one still has to philosophise in the Western mode. (Eboussi Boulaga 1977: 219; English translation from Wolff 2016: 445)

The predicament of African philosophers referred to here by Eboussi Boulaga is representative of the difficulty faced by those writing philosophy from the periphery.

In opposition to hegemony, peripheral groups would appear to have two choices: they can either attempt at dislodging the hegemonic group by coopting the empty signifier for their own purposes, which leaves the structure of power relations intact but working in favor of the periphery (which becomes the hegemonic center if their attempt is successful), or they can oppose or decentralize the very empty signifier itself as representative of the hegemonic system. Of the two options, the first appears strategically more prone to success, to the extent that one can coopt the authority conveyed by a particular empty signifier, while the latter strategy prevents the cooption of the authoritative tools set by the center.

With regard to the notion of lixing, the two strategies outlined above can be exemplified by the evolution of Liang Shuming's (梁漱溟; 1893-1988) thought between 1921 and 1949, the dates of his publication of Eastern and Western Cultures and Their Philosophies (東西文化及其哲學) and Fundamentals of Chinese Culture (中國文化 要義) respectively. In the earlier work, Liang remains ambiguous with regard to what he calls lizhi (理智), a term closely associated with lixing (both can and often are translated to 'reason' in English): while it plays a central role in establishing scientific knowledge about the external world, it is also responsible for a number of ills Liang saw as characteristic of modern Euro-American culture: the growing gap between subject and object, the tendency to dissect and fragment an external realm which should instead be regarded as holistic, and the emergence of a utilitarian and dehumanized rapport between individuals (Liang 2005a: 485; 2011: 184). Zhijue (直覺; intuition), which Liang associates with Chinese culture and Confucianism, could contribute to alleviate these modern symptoms by closing the gap between the individual on the one hand and 
society and nature on the other. Chinese intuition was destined to save world civilization from the devastating effects of Euro-American rationality. ${ }^{11}$

In Fundamentals of Chinese Culture, however, Liang employs lixing rather than zhijue to designate the intuitive and holistic apprehension of reality. ${ }^{12}$ While this may appear rather odd to readers unfamiliar with the dynamics of modern Chinese philosophy, it must be remembered that lixing remains a heavily connoted term in Chinese, and easily lends itself to a Neo-Confucian reading, at least to the extent that both $l i$ (理) and xing (性) were central components of the Neo-Confucian debates on human nature, the rapport between $l i$ and $q i$ (氣), and self-cultivation. Following Wang Yangming (王 陽明; 1472-1529), lixing could easily be interpreted as that within human nature (xing) which enables our accessing the $l i$ (principle, pattern) of things. ${ }^{13}$ This explains why Liang went on to define lixing as the innate human faculty to intuit the good nondiscursively, a meaning which essentially parallels the role of liangzhi (良知; innate moral knowing) in Wang Yangming's thought.

I would like to make two points with regard to Liang Shuming's use of lizhi and lixing. First, it exemplifies the complexity of dealing with a term that possesses, in modern Confucian discourse, two distinct referents. On the one hand, lixing can be used as a translation of 'reason' or 'rationality' 14 - this is how it has been employed by most Chinese intellectuals throughout the twentieth century-and on the other hand, it can also refer back to a Neo-Confucian constellation of meanings, related to one's ability to access moral truths internally. ${ }^{15}$ For simplification, I call the former 'lixing-asrationality' and the latter 'lixing-as-liangzhi.'

Second, and this is my main point, the evolution of Liang's conceptualization of lixing highlights two differing strategies that can be employed in opposition to notions which were and still are emblematic of the hegemonic position of Euro-American knowledge production. On the one hand, one can reject the concept as inadequate or, perhaps better still, affirm its value but as a human faculty inferior to intuition, which can be made to represent the Chinese or Confucian tradition. On the other hand, one can coopt the term lixing by redefining it in a way that peripherizes Euro-American conceptions of the term and places Chinese or one's personal content in its place. In short, one can reject or decenter the empty signifier itself in order to oppose the particular content of the hegemon filling it in or one can coopt the empty signifier for one's particular purposes, effectively decentering not the empty signifier itself but the hegemonic content that occupies it. In what follows, I argue that it is precisely this last strategy Tang adopts in Cultural Consciousness and Moral Reason.

\footnotetext{
${ }^{11}$ On intuition, see Liang 2005a: 452-457; Liang 2011: 141-148.

12 On lixing, see Liang 2005b: 122-139; 2010: 163-183. On the replacement of 'zhijue' by 'lixing' in this work, and on the topic of the influence of Bergson on Liang's notion of intuition, see An 1997.

${ }^{13}$ For a philosophical overview of the notions of xing and $l i$ in Neo-Confucianism, see Angle and Tiwald 2017: 23-70.

${ }^{14}$ Lixing is a neologism of Japanese origin (pronounced 'risei' in Japanese) referring to 'reason' or 'rationality.' Its first appearance in Chinese probably dates back to its use in the work of Wang Guowei (王國維; 18771927) from 1902 on. See Huang 2008: 345n33.

${ }^{15}$ Lixing could also have a third referent, that of 'essential nature,' or 'true thusness' (zhenru 真如), in Buddhist discourse. See Muller 2020.
} 


\section{Situating lixing Within Cultural Consciousness and Moral Reason}

Born in Sichuan (四川) in 1909, Tang Junyi graduated from National Central University (guoli zhongyang daxue 國立中央大學) in Nanjing (南京) in 1932 before taking a position as lecturer and then professor at the university. In 1949, Tang left the mainland for Hong Kong, where he contributed to the foundation of the New Asia College (xinya shuyuan 新亞書院). ${ }^{16}$ During this exilic period, Tang wrote a number of books on or of Chinese philosophy which contributed to his being retrospectively celebrated as one of the most important New Confucian intellectuals. ${ }^{17}$ Written during the tumultuous period between 1947 and 1952, Cultural Consciousness and Moral Reason is an ambitious work aiming at a systematic philosophy of culture the self-professed goal of which is that of proving that culture is moral, in the sense that it provides humanity with the potential to free itself from its own animality. ${ }^{18}$

Insofar as it enables humanity to transcend the limitations of the here and the now, lixing plays a central role in this freeing process. In the second preface to his work, Tang defines lixing as 'the human nature (xing) that can manifest $l i$ [the principle] and conform to $l i$. We can also say that $l i$ is human nature. Lixing is what Chinese Confucians call xingli [the principle of human nature], which is the substance or selfhood which makes [...] our transcendent self what it is' (Tang 1974b: 19). Referring, within this context, to universal moral principles rooted in a metaphysical source (tian 天), the inner $l i$ of human nature should not be confused with the external $l i$ following the dictates of the laws of nature, since the latter are devoid of any sense of morality, freedom, or self-determination. The distinctiveness of lixing precisely resides in its ability to transcend what does not conform to li, what is feilixing (非理性), although what Tang has in mind here with regard to feilixing are not those phenomena that defy rational explanations, but rather those that do not conform to the moral pattern which is situated in our mind. Desires, past habits, and what Tang calls 'natural mental dispositions' (those that are not self-conscious and that do not emanate from our inner moral faculty) all belong to this category of feilixing, in the sense that although they possess their own $l i$, this $l i$ not only differs from that which makes up the metaphysical moral agency of human nature, it also limits it (Tang 1974b: 42-43).

Lixing constitutes the site of human agency (neng 能 as opposed to suo 所) which is situated within the human mind (心 $x$ in), and, as the autonomous source of our agency, as the unmoved mover, it should be understood as transcendent (Tang 1974b: 20). When we act in conformity with lixing, we 'transcend the material and embodied world of form and transcend our natural desires, our natural instincts, our natural mental dispositions, etc.' (Tang 1974b: 19-20). This transcendence from the realm of nature in turn enables us to master the world of form as well as natural desires and instincts.

Tang's notion of lixing is inscribed in a metanarrative of human evolution which views culture as an ever-expanding moral phenomenon. Cultural phenomena such as

\footnotetext{
${ }^{16}$ On the significance of Tang's exilic experience, see Fröhlich 2013.

${ }^{17}$ On the retrospective creation of New Confucianism, see Makeham 2003.

${ }^{18}$ It should be noted that while Cultural Consciousness and Moral Reason mainly takes the form of a philosophy of culture, it also includes chapters that in and of themselves could be categorized as political philosophy, philosophy of religion, moral philosophy, etc. In other words, a number of branches of philosophy are subsumed within Tang's philosophy of culture in a manner that suggests the author was seeking for an allencompassing, coherent system.
} 
the family, the economy, politics, science, philosophy, literature, art, and religion, among others, are moral in the sense that they contribute to a transcendence from, and mastery of, our natural instincts and desires, necessary preconditions for the development of a self-conscious form of morality. The family, for example, is characterized by Tang as providing an unconscious means of realizing the moral self, since before I was born, I existed as potentiality in my parents; I was my parents. This enables me to take them as myself and transcend the narrow confines of selfishness. It is this initial, non-conscious form of self-transcendence that can then be projected onto the whole universe later on, when realizing (following Zhang Zai 張載; 1020-1077) that the whole universe is my parents (Tang 1974b: 78-79).

Although Tang subscribes to a Darwinian conception of evolution which regards culture and the human mind as its products, he remains an idealist, since within evolution, 'a principle, dao [道], or life spirit that transcends the material world or that causes the material world to transcend itself is continuously manifested' (Tang 1974b: 648). Human history is an expression of the same spirit: it evolves along a predetermined course which sees the growth of the moral, transcendent self at the expense of the self taken over by natural instincts and desires. And yet, despite its following a predefined path, history is always prone to reverse its course if humanity fails to act according to lixing, giving free reign to the nonrationality (feilixing) of natural desires and instincts instead (Tang 1974b: 17). Humans are in fact entrusted with what I would call the messianic task ${ }^{19}$ of completing the universe: of gradually reshaping, generation after generation, nature into culture, matter into spirit, natural desires and instincts into transcendence, selfishness into selflessness, and animality into morality.

The messianic task entrusted to humanity can be accomplished thanks to the human capacity for self-consciousness and self-determination. Tang narrates a process whereby the ideals upon which the self acts are initially inherited from the past and from others; one's actions remain, at this level, entirely determined by the environment and the past, as well as by what Tang calls 'the mechanisms of natural mentality or natural life desires' (Tang 1974b: 35-36, 49). But then, through the process of acculturation, one gradually learns to transcend one's selfish, natural desires. This enables one to acquire self-consciousness, which represents, within Tang's metaphysics of the self, the watershed moment wherefrom human free will and self-determination emanate. This is because once one has achieved self-consciousness and self-transcendence, one can reflect, from a transcendent vantage point, on the ideals upon which one has acted until now, submitting each of them to the test of lixing so that only those ideals that are vetted by it can be acted upon in the future. This is why Tang claims that to 'free oneself from prevalent customs is the root of studying to become a sage' (Tang 1974b: 573): one needs to transcend spatio-temporal limitations before recognizing what is good and what is bad of tradition. It is through this process that the self can free itself

\footnotetext{
${ }^{19}$ On the 'messianic vision' of Tang, Thomas Fröhlich notes that 'in looking back on his personal and intellectual development, [Tang] professed that early in his life he had felt responsible for setting out on a mission to save humanity. [...] It is difficult to know the degree to which this messianic self-awareness actually has come to bear in Tang's philosophical writing. [...] It seems likely nonetheless that he was deeply convinced throughout his life that he should strive to guide the minds of his fellow men to the highest realm.' Fröhlich 2017: 82 (on this, see also 83n61).
} 
from determinism and achieve liberty as well as self-mastery, the latter being conceptualized as a mastery of both internal and external nature. ${ }^{20}$

Within this metanarrative is inscribed an analogy between human history and individual self-development, both understood as a gradual passage from nonrationality to lixing and from determinism to human autonomy. At both levels, the human course is at first entirely determined by desires and instincts; by the principle of nature, in short. But then culture gradually enables humanity and the individual to transcend the determinism of nature, find within itself a metaphysical source of moral normativity through lixing, achieve self-determination qua self-transcendence, and then set out to transform the external world in the form of lixing. While what Tang calls 'cultural activities' (wenhua huodong 文化活動) used to be, at the beginning of evolution, the mere by-products of selfish desires which nonetheless possessed the potential to give rise to self-transcendence, they gradually become, throughout history, the intended product of self-conscious individuals working on the messianic task of completing the universe by moralizing it in the shape provided by lixing.

I will come back to this messianic task in a moment. For now, I would like to note how Tang's vision of the self emulates the discourse of the Enlightenment in its positing lixing (rationality) as the source of the human ability to escape determinism and choose in a state of radical freedom vis-à-vis both the past and the other. ${ }^{21}$ In fact, Tang's depiction of self-consciousness and self-determination echoes Charles Taylor's portrayal of the punctual self of radical Enlightenment, as 'the disembodied ego, the subject who can objectify all being, including his own, and choose in radical freedom' (Taylor 1976: 35). Just as in the case of the punctual self, in which 'radical objectivity is only intelligible and accessible through radical subjectivity' (Taylor 1989: 176), the universal comes about, in Tang's discourse, only once one has freed oneself from all that is external and material and has reconnected with an inner core functioning as a gateway to the universal.

Tang's reconceptualization of the subject around the faculty of lixing therefore bears the potential for the kind of radical iconoclasm one could expect from the punctual self - after all, as we saw above, to 'free oneself from prevalent customs is the root of studying to become a sage' for Tang - although this potential is ultimately subdued, in Tang's discourse, by the fact that once the subject looks back it cannot but recognize the normativity of at least significant dimensions of the Confucian tradition. Lixing, as I hope will become clear in a moment, allows for a fusion of trans-historical and traditional sources of normativity, but a fusion that can nevertheless be presented as fulfilling the necessary condition of autonomy constitutive of the philosophical field, and thus escape the potential criticism that Confucian philosophical enterprises such as Tang's ultimately rest on the heteronomous authority of tradition and the classics.

Lixing thus plays a role structurally similar to that of rationality in Enlightenment Europe: it is the unmoved mover within the self, the source of human transcendence, the gateway through which the self can experience or think the universal despite the

\footnotetext{
${ }^{20}$ On this, see Tang 1974b: 35-37, 48-50. This conceptualization of lixing echoes that of Zhang Dongsun (張 東荪; 1886-1973) in Rationality and Democracy (理性與民主; 1946), in which Zhang posits rationality as that which enables humanity to free itself from determinism and its own animalistic nature in order to establish an ideal and choose a future for itself. Zhang 1974: 2.

${ }^{21}$ Tang states that in lixing (rational) acts, one must 'criticize one's own ideals, and repudiate and eliminate those elements in them that are not one's own...' Tang 1974b: 221.
} 
inescapable finitude of the human condition. As his equation of lixing with the NeoConfucian notion of xingli shows, however, Tang's lixing does not merely emulate Enlightenment rationality; it ultimately refers to a Confucian metaphysical source of morality within the self. It is at this level that Tang takes up one of the most important notions of modern European philosophy, and while retaining its basic function- that of providing humanity with a gateway from particularity to universality - he fills it with a content that is particular to Tang's (Confucian) project. This will become clearer if we take a closer look at Tang's ambiguous conceptualization of the way lixing works in practice.

\section{Filling lixing with Particular Content}

Given the centrality of the concept in his philosophical edifice, Tang remains rather vague as to the actual functioning of lixing. Through what process can lixing reveal the internal $l i$ situated at its core to the transcendent self? How can we ensure our judgments originate in lixing rather than selfish instincts and desires disguised as lixing? Tang acknowledges this danger (Tang 1974b: 107) and appears to offer two means through which one can ensure that what one takes to be lixing indeed is. The first one is liangzhi: an innate moral faculty situated within our mind which manifests itself as an intuitive good or bad feeling toward a particular action. As long as one acts following liangzhi, one can be assured that one's actions will remain both moral and in accord with li (heli 合理) (Tang 1974b: 371). At this level, however, one is not selfconscious yet, and there remains a chance that one's liangzhi finds itself polluted by selfish desires and instincts (Tang 1974b: 544). ${ }^{22}$

To ensure the moral law one intuited in actu is indeed lixing, ${ }^{23}$ one needs to become self-conscious. The second method involves a process of deliberation that seeks an answer to two questions: first, would the activity be recognized as lixing by anyone, at any time in history and in any place (this is Tang's version of the categorical imperative), and two, does the activity impede other lixing activities or does it contribute to bringing about other lixing activities? (Tang here assumes that only those activities that are feilixing (nonrational) impede the development of lixing activities; two lixing activities cannot but cohabit harmoniously and reinforce one another.) By reflecting on one's activities in such manner, one can be assured that those activities

\footnotetext{
${ }^{22}$ In a later article published in 1972, 'The Epochal Significance of Wang Yangming's Study of Innate Knowledge' (Wang Yangming zhi liangzhi xue zhi shidai yiyi 王陽明之良知學之時代意義), Tang presents EuroAmerican imperialism as a historical instance in which Europeans and Americans made use of liangzhi in an evil (zui'e 罪惡) manner, in an attempt at imposing the values they recognized as universal on the other. For Tang, decolonization therefore manifests a need, among the formerly colonized, 'to spontaneously and autonomously determine a value criterion through a choice manifesting their own innate knowledge' as opposed to that of the colonial powers. Tang's use of lixing as empty signifier could therefore perhaps be put within the context of this effort to decolonize or at least 'de-imperialize' China. For the translation of the related excerpts from the article and a discussion of them, see Van den Stock 2016: 68-70. I thank one of the blind reviewers of this article for pointing this out to me.

${ }^{23}$ Lixing is employed by Tang to denote the faculty enabling our access to moral laws, but it is also used as an adjective to denote whatever follows the dictate of that faculty. I try, in what follows, to do justice to this double use by employing the transliteration 'lixing' both as a noun and as an adjective, notably in order to avoid having to use the adjective 'rational,' which, as we will see, is a problematic translation given Tang's understanding of lixing.
} 
that are not entirely lixing will be revealed as such to the transcendent subject, who will then be able to eradicate them and replace them with truly lixing ones. The ultimate goal of self-reflection is that of synthesizing the various moral laws acquired through liangzhi into an ever-greater moral law or imperative that will apply to an ever-greater number of situations (Tang 1974b: 371-372).

It would at first sight appear that Tang accommodates, under the notion of lixing, both Confucian liangzhi and a 'Western' form of reason. It should be noted, however, that in the model introduced above, rational reflection relies on liangzhi as the provider of intuited moral truths. To complicate matters further, Tang also suggests that liangzhi itself is the capacity to self-consciously judge whether an activity is lixing and would be recognized as such by everyone (the categorical imperative) (Tang 1974b: 533). This suggests that self-reflective rationality itself (i.e., the second method above) is also liangzhi; perhaps a second-order, self-conscious liangzhi.

It is uncertain, however, whether Tang believed that this self-conscious reflective process itself should be regarded as liangzhi or not. In one instance, he explicitly distinguishes between utilitarianism (can a cultural activity help the development of other cultural activities in the future?), rationalism (would anyone, anywhere, and at any time agree that a cultural activity is indeed lixing?), and intuitive liangzhi (is a cultural activity vetted intuitively by liangzhi?). But Tang also maintains that these three perspectives (guandian 觀點) on moral judgment are in fact one perspective divided into three for the sake of explanation (Tang 1974b: 532-533). The last claim can be interpreted, I suggest, in at least two different ways. On one reading, the three methods provide different means to reach the same conclusions, although ultimately we can assume that the scope of moral activities vetted by liangzhi is broader than that recognized as lixing through utilitarian and rational means. This is how Thomas Fröhlich interprets this passage, as implying,

first, that correct moral judgments are not an exclusive matter of liang zhi, and yet also, second, that any correct moral judgment can be made by liang zhi. In other words, while moral judgments of utilitarian or rationalist provenance may be confirmed or rejected by liang zhi, the opposite is not necessarily possible. There are thus moral judgments made by liang zhi that remain outside of the scope of utilitarianism or rationalism. (Fröhlich 2017: 142-143)

Under this interpretation, liangzhi is not the sole source of moral judgments, although it remains the most reliable one.

Another way to interpret Tang's assertion that utilitarianism, rationalism, and liangzhi actually refer to a single perspective is to appeal to Tang's metaphysical assumption that a Universal mind (tianxin 天心) is shared by all and thus that metaphysical truths are always innately accessible to the subject. From this perspective, Tang's categorical imperative should perhaps not be understood in a Kantian sense, insofar as reflecting on whether an activity would be accepted by everyone as lixing or not is one and the same as reflecting on whether it has its origin in the metaphysical moral source within us, given that the latter is universally shared by all. Tang's categorical imperative could therefore be understood as involving the same method as that of liangzhi, insofar as the latter is regarded as an intuitive grasp of moral truths enabled by one's universal mind. Within this reading, the categorical imperative does 
not rely on intersubjective communication or the deployment of logical argumentation; rather, it is subsumed within the scope of liangzhi's dominion.

Unfortunately, Tang remains rather vague on this issue, and there is no indication, at least in this work, as to which interpretation should be regarded as definitive. ${ }^{24}$ Nonetheless, it is safe to say that liangzhi is either the sole legitimate source of moral laws or the dominant one according to Tang. In both cases, it appears that one's conclusions cannot be challenged through rational argumentation, nor can they be opposed by those who have not yet developed their ability to activate their universal mind. Tang's lixing, to the extent that it transcends rationality, is therefore nonrational, or at least it is so from the perspective of Euro-American philosophy.

By redefining lixing as an intuitive experience of the universal ultimately escaping to some extent the grasp of rational argumentation, Tang reinstates the authority of the figure of the Confucian sage. ${ }^{25}$ The sage, Tang maintains, has reached a metaphysical form of enlightenment through which he - and perhaps she? - has been able to distinguish what is lixing from what is not (Tang 1974b: 573). ${ }^{26}$ Now to the extent that Tang's work sets itself the goal of unveiling to the reader the ideal and lixinghua (理性化; rationalized) forms of culture that he or she should work toward implementing, while simultaneously presenting to the reader the means through which enlightenment can be gained, the legitimacy of the text's discourse relies on the implicit assumption that Tang, if not a sage, has at least access to the metaphysical source providing him with the ability to differentiate what is lixing from what is not. Lixing thus functions as a means through which both the author and his discourse can be authorized by universalizing them: after all, the author is in theory no longer Tang Junyi the historically-situated individual, but the universal mind (tianxin) that speaks through $\operatorname{him}^{27}$

\footnotetext{
${ }^{24}$ Fröhlich notes that 'in his use of the Chinese term lixing for "reason"' in his The Reconstruction of the Humanistic Spirit (Renwen jingshen zhi chongjian 人文精神之重建), published in 1955, 'Tang explicitly stated that reason in the sense of lixing is not to be reduced to the function of a 'universal lawgiver,' since it transcends human self-consciousness. He suggested that the term liang zhi may be used instead of lixing. By equating lixing with the non-conceptual and quasi transrational liang zhi, Tang obviously negated any identification of lixing / 'reason' with a calculating and instrumental type of rationality.' Fröhlich 2017: 130. It is also worthy to note that in the article 'My Choices with regard to Philosophy and Religion' (wo duiyu zhexue yu zongjiao zhi jueze 我對於哲學與宗教之抉擇) published in appendix to The Reconstruction of the Humanistic Spirit, Tang explicitly claims that liangzhi should be understood as the master (zhuzai 主宰) in charge of determining the value not only of scientific activities, but of all human activities in general. See Tang Junyi 1988: 586 and the following English translation: Tang 1974a: 28.

${ }^{25}$ Rafael Suter provides an analysis of the way the notion of intellectual intuition in Mou Zongsan's philosophy enables him to restore the authority of tradition and of the sage, since 'because this intellectual intuition allegedly is not susceptible to linguistic representation and discursive explanation, it has to invoke the authority of the teacher warranting its validity.' See Suter 2018a and 2018b (p.516 for the quote).

${ }^{26}$ Given this understanding of Confucian sagehood, it is not clear how the sages of the past failed to understand the value of democracy, as Tang claims (291). Perhaps this can be accounted for by the fact that even the sage does not have access to the entire field of lixing. This would also explain why historical progress remains rather slow: those who can guide us can only take us part of the way toward the union of heaven and the human. But note how this reading would assume that the Confucian sages of the past not only unacknowledged the value of democracy, but were in fact mistaken when upholding that the figure of the sage-king, for example, represented the highest political form that could be achieved. If the sages mistook what is feilixing (nonrational) for what is lixing in this particular case, however, how can we know that they were not entirely mistaken on other issues? Tang did not address these issues in this work.

${ }^{27}$ This explains why Tang at times depicts language not as a means of intersubjective communication, but rather as a medium through which one can communicate from and with the spirit of the universal self. See Tang 1974b: 58.
} 
In this respect, the purpose served by lixing is reminiscent of the uses some intellectuals made of sagehood in the past: it is a tool of universalization which is said to be universal itself (everybody can become a sage), although in actuality it is only embodied by an elite group of enlightened individuals. Lixing serves, within such a reading, as a tool of inclusion and exclusion through which universalized particularsby which I refer both to lixing itself and to the various cultural activities it authorizes, such as the Confucian family, private property, democracy, etc. - can be monopolized by a particular group or individual. It is precisely the gap between the claimed universality of lixing and its full actualization in the case of an elite that allows Tang to employ lixing as an empty signifier: as a universal that is nevertheless a form of lack; a lack requiring that a chosen few guides humanity on the right path.

In short, Tang's conceptualization of lixing presents itself as an overturning of Enlightenment rationality, insofar as it rests on a nonrational intuition, although it ultimately serves purposes that are both similar to and diverging from Enlightenment rationality. This is precisely how empty signifiers work: in order to coopt the signifier for their own purposes, those outside the hegemonic centers of power must retain and approve of the (hegemonized) linguistic system within which the empty signifier is inscribed and which provides it with authority (in Tang's case: lixing-as-rationality as the source of human transcendence, self-determination, and freedom), but fill it with particular content in a way that is meant to universalize their particular perspective (in Tang's case: lixing-as-liangzhi, understood as an intuitive grasp of moral truth).

\section{Lixing as Source of all Universals}

Apart from enabling Tang to universalize his agenda by presenting it as the ultimate content filling in the empty signifier, lixing also serves, in Tang's text, as what I would like to call a foundational empty signifier, and it does so in two different ways. First, through its associations with the notions of autonomy and self-determination, lixing fulfills the purpose of a legitimating ground upon which the philosophical game can be played. I will come back to this issue in a moment, but for now I would like to discuss the second sense in which lixing can be understood as a foundational empty signifier: that is by serving as basis upon which all other universals can be established.

This second function can be exemplified by Tang's characterization of the role the transcendent self deploying lixing plays in bridging the gap between reality and ideality. Through the process of achieving self-transcendence and self-mastery, one progressively realizes that at one's core stands a Universal mind (tianxin) that is not properly one's own, but is rather shared with every other human being (Tang 1974b: 362,671 ). To access the Universal mind entails that the self is no longer limited to one's body or one's mind, no longer erected in opposition to the other. The self becomes, in the process, one with humanity and the metaphysical source of the universal.

But Tang's discourse of union of heaven and the human (tianren heyi 天人合一) does not end when one bridges the gap between self and other. The ultimate goal of this process of self-mastery is rather to discover, through lixing, ideals that are universal before transforming these ideals into reality in the external world. Cultural activities that lead to the realization or objectification of inner, lixing ideals are what Tang calls 
'spiritual activities' (jingshen huodong 精神活動) (Tang 1974b: 31). Once the inner ideal is objectified in the external realm, and particularly in cultural activities, it can help others, through the process of acculturation, achieve self-consciousness, and seek for themselves the realization of other ideals that have not yet been realized externally. Through this process, the external $l i$ of society is gradually reshaped in the form of the internal $l i$ vetted by the Universal mind. This is how Tang redefines the ultimate goal of union of heaven and the human. ${ }^{28}$

To the extent that the goal is to lixinghua (rationalize) the universe, lixing presents itself as a lack; as what should be but is not yet. In effect, it is precisely this lack-the world as it should be - that is filled in by the content of Tang's text, which provides the reader with an outline of how the world ought to be, one cultural activity at a time, based on the authority of lixing, the universal provider of universality. By revealing the lixing foundation of each cultural activity to the readers, Tang hopes to induce selfconsciousness in them, so that they will 'reject today's views that call for the obliteration of the family and the state' (Tang 1974b: 107). As such, Tang's work often reads as an attempt to preserve traditional models of societal formations against the double threats of modernity and communism; certainly Tang endeavors to re-authorize the Confucian family system - centered on marriage, filial piety, brotherly love, and patriarchy - private property, the state, and social hierarchy, to name but a few, by showing how each of them is lixing. ${ }^{29}$

Of course, Tang is not merely a conservative; his vision also incorporates significant borrowings from Euro-American modernity, such as science, democracy, and capitalism. But overall, we can say that although in theory Tang's notion of lixing possesses the same potential as European rationality to reject tradition as a limitation imposed on the autonomous self, in practice it often serves as a means through which traditional outlooks and practices can be re-authorized. Just as Tang reversed the meaning of lixing-as-rationality by redefining it as a nonrational form of intuition, he similarly overturns the iconoclastic function rationality has played in the context of Enlightenment Europe, rather putting lixing to the task of re-authorizing at least significant aspects of tradition. Yet in the cases of both lixing and rationality, what we have is not only a concept filled with particular content yet claimed to be universal, but also a means of authorization through which other particulars, such as the Confucian family system or democracy, can be universalized. ${ }^{30}$

Lixing, in short, has the unique ability of revealing the gap between reality and ideality before translating the former into the latter. Lixing does this first by liberating the subject from the determinism of what is before bringing about a normative yet equally inescapable determinism; a teleological force that pulls us toward the end-ofhistory-as-ideality. It is precisely in its ability to legitimize particular ideals - such as the Confucian family system - by presenting them as predetermined by a natural yet

\footnotetext{
${ }^{28}$ The aim is not to get rid of all natural desires and instincts, but rather to moralize them and make them serve the purpose of self-transcendence. Tang 1974b: 81-82.

${ }^{29}$ For Tang's defense of these traditions, see Tang 1974b: 69-73 (on marriage), 73-85 (on filial piety), 85-93 (on brotherly love), 114-119 (on patriarchy), 130-138 (on private property), 197-204 (on social hierarchy), and 215-233 (on the state).

${ }^{30}$ Tang clearly states that although filial piety might appear to be a concept which only applies to China, it is in fact universal, or at least it should be. See Tang 1974b: 73-74.
} 
normative faculty within our mind that lixing can serve as a foundational empty signifier: as the only filled universal that can fill in all other universals.

\section{Lixing as Foundation of the Philosophical Game}

By claiming to have discovered the lixing basis of all cultural activities, both those that presently exist and those that ought to exist, Tang's text reads as a bridge connecting the shores of reality and ideality. It reads, in other words, as a symbolic enactment of the idealization and rationalization of reality, but one that legitimizes particular cultural phenomena by draping them in the cloth of universality. ${ }^{31}$ It is a whole world of particulars that is made to fill in the content of lixing as empty signifier.

In order for lixing to serve its purpose in universalizing particulars, however, it is imperative that the power dynamics of lixing qua empty signifier be hidden from the view of the readers. Empty signifiers can hegemonize particular contents only to the extent that they are not perceived as socio-political means of hegemony. This explains why the notions of autonomy and self-determination take a prominent place not only in Tang's philosophical edifice, but in the philosophical game in general. Philosophy's business of translating particulars into universals, in short, is that of filling in empty signifiers with particular contents in order to hegemonize them; and this hegemonizing function can be successful only to the extent that its practice is believed to take place in complete independence, if not isolation, from socio-political struggles for power.

This takes us back to the first use of lixing as foundational empty signifier pointed out above. The equivalence that is drawn between lixing/rationality on the one hand and the notions of autonomy and self-determination on the other, both in Tang's philosophy and in the discourse of the Enlightenment, can be understood as metacommentaries on philosophical thinking and philosophical textuality. Tang's narrative on the individual gaining access to lixing through self-transcendence provides an implicit account of the origin of the text itself, and one that is meant to authorize its inclusion in the philosophical game.

As we saw, Tang's text clearly implies that it is the product of an author having access to lixing and therefore writing in a state of autonomy vis-à-vis the deterministic aspects of history and culture. The performative function of this discourse, from the point of view of the philosophical game, is that of instituting Tang and the text as autonomous and therefore as having a privileged access to the universal which resides in the faculty of lixing. The manner in which lixing and self-transcendence function as a means of purifying the subject from any form of determinism or socio-historical and physical embeddedness in the discourse of the text mirrors the manner in which they enable the text to be symbolically elevated to a state of disembodied transcendence, in the sense that they form a medium through which universality can be translated into writing; through which ideality can be symbolically made real.

The form and the content of the text thus authorize one another: the discourse on self-transcendence, autonomy, and lixing deployed by Tang is meant to authorize his text as autonomous and lixing, and not as the product of an author who is particularly

\footnotetext{
${ }^{31}$ It should be noted that ideality remains universal in Tang's view, given that ideals are the product of a metaphysical source shared by all and accessed through lixing.
} 
skilled at playing the philosophical game within the context of a global struggle for power. Lixing and rationality qua autonomy thus serve the purpose of hiding one's involvement in a philosophical game marked by one's desire to seek power in writing, and represent a condition sine qua non of one's inclusion in the game.

What remains hidden underneath the universalizing function ascribed to lixing by Tang and rationality by the European Enlightenment is in fact the discursive function of lixing/rationality as empty signifier, which is that of seeking hegemony by universalizing one's particular discourse. The fact that lixing/rationality authorizes one's project by universalizing it is meant to be hidden from the view of the reader to the extent that this universalizing function is projected onto a natural faculty of the human mind which transcends the politics of writing philosophy. One of the most important means through which discourses can be hegemonized, in other words, is precisely that of avoiding to present one's views as contending in an arena of competing views, but rather to claim that one's conclusions were reached solely by following the natural path cleared up by reason/lixing. Tang in fact never directly opposes his lixing to Euro-American rationality; he never situates his discourse in the mundane struggle for power that is characteristic of the philosophical milieu. But this absence of positioning in relations of power is nevertheless a form of positioning; one that is particularly useful for discourses claiming universality, such as that of philosophy.

\section{Empty Signifiers and Violence}

Lixing's reliance on a nonrational form of intuition, in Tang's work, makes it particularly subject to being coopted by opposing forces wishing to hegemonize their perspective, to the extent that such intuition can be claimed by anyone who is wellversed in the philosophical game Tang plays. There is an inherent danger in positing such an arbitrary tool of authorization of discourses: while Tang often uses it in intelligent and non-violent ways, there are instances in which lixing is put to the task of reauthorizing patriarchal relations of power and naturalizing a conception of women as inherently weak and passive (even though in theory Tang claims that women and men are equal). ${ }^{32}$ These examples should suffice to remind us of the potential of violence inherent in discourses that rely so heavily on the universalization of particular perspectives.

At first sight, it would seem that Enlightenment rationality would be better equipped to oppose the arbitrariness of a notion like lixing: after all, rationality is ideally deployed in a discursive space that allows for disagreement. The intersubjective and transparent nature of rationality would therefore make it less susceptible to being coopted by various factions or individuals in order to hegemonize their agenda. After all, rational arguments are intersubjective and aim at convincing the other, while lixing depends on the authority of the speaker. While this

\footnotetext{
32 Tang 1974b: 41 and 117-118 (on women being weak), 114 (on equality between men and women). See also how Tang's discussion of filial piety and brotherly love (you 友) is entirely androcentric: 81-86. I also find Tang's notion of the integral (zhengti 整體) nation-state particularly prone to serving totalitarian agendas, despite Tang's explicit rejection of totalitarianism. On this, see Tang 1974b: 221-229.
} 
might hold true in theory, we cannot but acknowledge the fact that rationality has been employed as an empty signifier in order to hegemonize Euro-American perspectives. Rationality has often been put to the task, and often still is, of legitimizing a divide between those nations that are somewhat obeying its principles and those that follow the irrationality of a pre-modern order said to be unfree. Colonialism and imperialism were in fact repeatedly legitimized through a discourse which presented the various others of Euro-America as irrational, premodern individuals whose emancipation rested on the shoulders of the colonialists. The discourse according to which Europeans and North Americans were in charge of the messianic task of actualizing the universal potential of rationality in everyone thus served the purpose of hiding the fact that such a colonial program rested on a desire to reshape all others in the form of the self.

Facing such an important tool of authorization and legitimation, Chinese philosophers who wanted to oppose the hegemon had two options: either they could discard lixing or relegate it to an inferior position, or they could coopt the concept to promote their own agenda. Given that lixing was already widely accepted as an authoritative concept in modern China, the first approach ran the risk of being simply rejected as a resurgence of the 'irrationality' which was supposedly pervasive in China's past. As such, one's discourse had better chances of being effective if it accepted the authoritative nature of lixing while modifying its meaning, even to the extent of reversing what lixing was meant to translate in the first place. This is the gamble that Tang makes when redefining lixing as nonrational intuition.

In doing so, Tang opposes the hegemonic position of Euro-American philosophy symbolized by the importance the notion of lixing had taken in modern China, but he does so in a manner that leaves intact the mechanism of philosophical production of hegemonic discourses. Tang's lixing is not immune to the danger of legitimizing differing forms of violence and oppression that we saw at work in the relation between rationality and coloniality, although this danger remained symbolic and was never actualized in the case of lixing, for the simple reason that Tang's discourse was deployed from outside the centers of hegemonic power and against it, and insofar as its implicit hope to replace the hegemon never materialized, it never played any central role in legitimizing any form of oppression in actuality.

This reading of lixing situates Tang's work in the socio-historical world, in the sense that lixing-as-empty-signifier was deployed by Tang in opposition to hegemonic centers of power, which include not only the West but also the Chinese Communist Party; after all, Tang clearly presents his moral-cultural idealism as the alternative to historical materialism. ${ }^{33}$ The dialectic between ideality and reality taking shape in empty signifiers enabled Tang to imply that while these hegemonic powers were reigning over the world as it then was, their dominion did not and would never extend to what ought to be. Tang's text, which reads as a symbolic enactment of the gradual idealization of the world as Tang intended it, was therefore composed as a symbolic third force that would avoid the pitfalls of both Euro-American and Communist hegemonies.

\footnotetext{
${ }_{33}^{33}$ For Tang's explanation of why he opposes historical materialism from an idealist perspective, see Tang 1974b: 15-19, 647-648.
} 


\section{Conclusion}

To sum up, lixing-as-empty-signifier works by producing a gap between ideality and reality. This gap enables Tang to symbolically reshape reality in the form of a lack which can be filled by the particular program he promoted. Compared to other empty signifiers, such as the notion of peace discussed above, lixing is unique in that it is a foundational empty signifier: it serves as the basis upon which a whole edifice of universalized particulars can be established, while at the same time authorizing one's inclusion in the philosophical game. This explains why lixing was, in modern China, a contested notion over which various groups and factions (May Fourth iconoclasts, Marxists, Liberals, Confucians, etc.) fought in order to hegemonize their own agendas.

Coming back to the topic of philosophy's game of inclusion and exclusion with which I began, we can say that lixing enables Tang to play the game of philosophy without the explicit need to justify or legitimize his presence in the game. As Thomas Fröhlich notes in his monograph on Tang, "the term "lixing" is highly ambivalent in the context of modern Confucianism and it is sometimes difficult to determine whether Tang was using it as neologism (thus referring to Western philosophical vocabularies of reason/rationality) or in relation to the semantic field of "liang zhi" [...]' (Fröhlich 2017: 130n97). I would suggest it is precisely the ambiguity of lixing, as referring both to 'rationality' and 'liangzhi,' that makes it possible for Tang to posit his work as partaking in the games of both Euro-American and Neo-Confucian philosophies, and therefore to inscribe Chinese philosophy within the legitimate framework required by the hegemon (a framework often implicitly accepted as authoritative by modern Chinese intellectuals). ${ }^{34}$ Moreover, by presenting his work as the product of a lixing which is not properly Tang's but is in fact the working of the Universal mind of humanity in him, Cultural Consciousness and Moral Reason can be made to appear as if its conclusions were reached in a state of absolute autonomy, so that even when the text seems eager to attack certain traditions, whether it be materialism, utilitarianism, or naturalism, it can claim to do so not from the perspective of someone who partakes in social struggles for power, but from that of a perfectly autonomous philosopher.

This highlights an important feature of philosophy's game: one needs to hide the fact that this game is situated in wider relations of power in order to sustain the fiction of autonomy which is constitutive of the game and which is a condition sine qua non of one's inclusion in the game. The notion of rationality certainly plays a central role in supporting this fiction, so much so that philosophers situated outside the hegemonic centers of power have felt that it was to their advantage to make use of the same notion, albeit in a radically new sense, to legitimize their presence in the game. Thanks to its ambiguity, lixing is a particularly clever means through which one can fuse the EuroAmerican and Neo-Confucian games and hopefully be legitimized in playing both.

Although Tang uses the rules of the game set up by the hegemon in order to oppose the hegemon, he does so by redefining lixing in a manner that reinstates the authority of

\footnotetext{
$\overline{34}$ Tang's use of lixing could perhaps also be understood as a response - of a philosopher 'writing back' to the center from the periphery - to what Olberding calls the "double bind" of Asian philosophies: "This double bind consists in the need to demonstrate that Asian philosophies offer novel elements not found elsewhere in the Western canon and in the need to make Asian philosophies conform to dominant existing interests, methods, and paradigms: Asian philosophy needs to be different, but never too different.' Olberding 2017: 1031. On this topic, see also Olberding 2015.
} 
the Confucian sage, and therefore in a manner that is most likely to be decried, in EuroAmerican philosophical circles, as non-universal, as particular to China only, and hence as of no interest to those philosophers who truly work in the domain of the universal (which 'incidentally' coincides with Euro-American philosophy).

By filling in lixing with particular content, Tang can universalize his discourse, but in doing so he will most likely be criticized by those situated in the hegemonic centers of powers. Whether Tang's attempt to universalize his conceptualization of lixing is recognized as legitimate or not, it should be noted, is entirely dependent on the text's reception by the readers, which is itself to some extent determined by the sociohistorical context within which the text is read. This is why Tang's discourse was ultimately little successful: the historical conditions were not appropriate for an acceptance of its vision of lixing, which relied heavily on Confucian traditions no longer regarded as authoritative. But within a different context, one in which Confucianism returns as a source of authority, notably for nationalist purposes, and in a historical period in which China's power slowly but steadily expands, one might wonder if Tang's discourse might not reappear in the future, perhaps in a slightly new form.

While this eventuality may or may not concretize itself, I suggest that in order to study the social rules of the game of philosophical writing, and situate them within the proper hegemonic struggles that inform them, it might be useful to look at those works that were written on the outskirts of the hegemonic centers, to the extent that their attempt at being included in the game tends to render the rules of the game more conspicuous. But we should remember that these rules apply to those working in the centers as well: in fact it is often by being oblivious of the fact that philosophy's game takes place in wider societal relations of power that those working in the centers manage not only to authorize themselves, but also to reproduce the very relations of power of which they remain unaware. I suggest that one way through which we can attempt to challenge this is by bringing to light the relations of power inherent in philosophical production, notably by looking at those works that cannot afford to be entirely unaware of them: that is, philosophical works situated outside the boundaries set up by the hegemon.

Acknowledgements I would like to thank Carine Defoort, Ralph Weber, Chang Yao-cheng, Abigail Xiaowei Wang, Silvia Toro, Milan Matthiesen, and the two blind reviewers for their comments on earlier drafts of this paper. The author benefited from financial support from the following two funding agencies at various stages of the writing process: Le fonds de recherche du Québec - Société et culture and the Swiss National Science Foundation.

Funding Open access funding provided by University of Basel.

Open Access This article is licensed under a Creative Commons Attribution 4.0 International License, which permits use, sharing, adaptation, distribution and reproduction in any medium or format, as long as you give appropriate credit to the original author(s) and the source, provide a link to the Creative Commons licence, and indicate if changes were made. The images or other third party material in this article are included in the article's Creative Commons licence, unless indicated otherwise in a credit line to the material. If material is not included in the article's Creative Commons licence and your intended use is not permitted by statutory regulation or exceeds the permitted use, you will need to obtain permission directly from the copyright holder. To view a copy of this licence, visit http://creativecommons.org/licenses/by/4.0/. 


\section{References}

Ames, R. T. (2010). Achieving personal identity in Confucian role ethics: Tang Junyi on human nature as conduct. Oriens Extremus, 49, 143-166.

An, Y. (1997). Liang Shuming and Henri Bergson on intuition: cultural context and the evolution of terms. Philosophy East \& West, 47(3), 337-362.

Angle, S. C., \& Tiwald, J. (2017). Neo-Confucianism: a philosophical introduction. Cambridge and Malden: Polity.

Bourdieu, P. (2000). Pascalian Meditations, translated by Richard Nice. Stanford: Stanford University Press.

Bruya, B. (2017). Ethnocentrism and multiculturalism in contemporary philosophy. Philosophy East \& West, 67(4), 991-1018.

Chen, Z. 陳振欵. (2015). Tang Junyi de rujiao lilun zhi yanjiu 唐君毅的儒教理論之研究 [A research on the religious confucian doctrine of Tang Junyi]. New Taipei City: Huamulan wenhua.

Cheng, A. (Ed.) (2005).Extrême-Orient, Extrême-Occident 27. Special issue : Y a-t-il une philosophie chinoise ? Un état de la question.

Chiu, K. P. (2016). Thomé H. Fang, Tang Junyi and Huayan Thought. Leiden: Brill.

Defoort, C. (2001). Is there such a thing as Chinese philosophy? Arguments of an implicit debate. Philosophy East \& West, 51(3), 393-413.

Defoort, C. (2006). Is 'Chinese philosophy' a proper name? A response to Rein Raud. Philosophy East \& West, 56(4), 625-660.

Defoort, C. (2017). 'Chinese philosophy' at European universities: A threefold utopia. Philosophy East \& West, 67(4), 1049-1080.

Defoort, C., \& Ge, Z. (Eds.). (2005, 2005-06, 2006). Contemporary Chinese Thought, 37, nos. 1, 2, \& 3.

Eboussi Boulaga, F. (1977). La crise du Muntu. Authenticité africaine et philosophie. Paris: Présence Africaine.

Fröhlich, T. (2013). The exilic prism of modernity: New perspectives on the post-war philosophy of Tang Junyi. Oriens Extremus, 52, 37-82.

Fröhlich, T. (2017). Tang Junyi: Confucian philosophy and the challenge of modernity. Leiden: Brill.

Garfield, J., \& Van Norden, B. W. (2016). If philosophy won’t diversify, let's call it what it really is. New York Times, May 11, 2016. https://www.nytimes.com/2016/05/11/opinion/if-philosophy-wont-diversify-letscall-it-what-it-really-is.html.

Huang, M. K.-w. (2008). The meaning of freedom: Yan Fu and the origins of Chinese liberalism. Hong Kong: The Chinese University Press.

Huang, Z. 黃兆強. (2010). Xueshu yu jingshi: Tang Junyi de lishi zhexue jiqi zhongji guanhuai 學術與經世: 唐君 毅的歷史哲學及其終極關懷 [Learning and statecraft: The philosophy of history of Tang Junyi and its ultimate concerns]. Taipei: Taiwan xuesheng.

Huang, K.-M. 黃冠閔. (2018). Gantong yu huidang: Tang Junyi zhexue luntan 感通與迴盪: 唐君毅哲學論探 [Affective communication and echo: An exploration of Tang Junyi's philosophy]. Taipei: Lianjing.

Laclau, E. (1996). Emancipation(s). London, New York: Verso.

Li, D. 李杜. (1982). Tang Junyi xiansheng de zhexue 唐君毅先生的哲學 [The philosophy of Mr. Tang Junyi]. Taipei: Xuesheng shuju.

Liang, S. 梁漱溟. (2005a). Dongxi wenhua ji qi zhexue 东西文化及其哲学 [Eastern and Western cultures and their philosophies]. In Liang Shuming quanji 梁漱溟全集 [The complete works of Liang Shuming], ed. Committee of the Academy of Chinese Culture (vol. 1, pp. 321-548). Jinan: Shandong Remin.

Liang, S. 梁漱溟. (2005b). Zhongguo wenhua yaoyi 中国文化要义 [Fundamentals of Chinese culture]. In Liang Shuming quanji 梁漱溟全集 [The complete works of Liang Shuming], ed. Committee of the Academy of Chinese Culture, vol. 3, 1-316. Jinan: Shandong Remin.

Liang, S. (2010). Les idées maîtresses de la culture chinoise, translated by Michel Masson. Paris: Les éditions du cerf/Institut Ricci.

Liang, S. (2011). Les cultures d'Orient et d'Occident et leurs philosophies, translated by Luo Shenyi. Paris: You Feng.

Makeham, J. (2003). The retrospective creation of New Confucianism. In J. Makeham (Ed.), New Confucianism: A critical examination (pp. 25-53). New York: Palgrave.

Metzger, T. (2005). A cloud across the Pacific: Essays on the clash between Chinese and Western political Theories Today. Hong Kong: The Chinese University Press.

Muller, C. (2020). "Lixing" 理性 [Essential nature]. Digital Dictionary of Buddhism. http://www.buddhismdict.net/cgi-bin/xpr-ddb.pl?q=\%E7\%90\%86\%E6\%80\%A7. 
Ng, W. (1998). T'ang Chun-i on transcendence: Foundations of a New-Confucian religious humanism. Monumenta Serica. Journal of Oriental Studies, 46, 291-322.

Olberding, A. (2015). It's not them, it's you: A case study concerning the exclusion of non-Western philosophy. Comparative Philosophy, 6(2), 14-34.

Olberding, A. (2017). Philosophical exclusion and conversational practices. Philosophy East \& West, 67(4), 1023-1038.

Suter, R. (2018a). Transmitting the sage's 'heart' (I): Unsealing moral autonomy-intellectual intuition and Mou Zongsan's reconstruction of the 'continuity of the way' (Daotong). Philosophy East \& West, 68(1), $223-241$.

Suter, R. (2018b). Transmitting the Sage's 'heart' (II): Instructing absolute practice - the perfection of the perfect teaching in Mou Zongsan's reconstruction of the Confucian Daotong. Philosophy East \& West, 68(2), 516-538.

Tang, J. (1974a). My option between philosophy and religion. Chinese Studies in Philosophy, 5(3), 4-38.

Tang, J. 唐君毅. (1974b [1958]). Wenhua yishi yu daode lixing 文化意識與道德理性 [Cultural consciousness and moral reason]. In Tang Junyi quanji 唐君毅全集 [The complete works of Tang Junyi] (vol. 20). Taipei: Taiwan xuesheng shuju.

Tang, J. 唐君毅. (1988 [1955]). Renwen jingshen zhi chongjian 人文精神之重建 [The reconstruction of the humanistic spirit]. In Tang Junyi quanji 唐君毅全集 [The complete works of Tang Junyi] (vol. 5) Taipei: Taiwan xuesheng shuju.

Taylor, C. (1976). Responsibility for self. In A. O. Rorty (Ed.), The identities of persons (pp. 281-299). Berkeley and Los Angeles: University of California Press.

Taylor, C. (1989). Sources of the self. Cambridge: Harvard University Press.

Van den Stock, A. (2016). The horizon of modernity: Subjectivity and social structure in New Confucian philosophy. Brill: Leiden.

Van Norden, B. W. (2017). Taking Back philosophy: A multicultural manifesto. New York: Columbia University Press.

Wolff, E. (2016). Four questions on curriculum development in contemporary South Africa. South African Journal of Philosophy, 35(4), 444-459.

Zhang, D. 張東荪. (1974 [1946]). Lixing yu minzhu 理性與民主 [Rationality and democracy]. Taipei: Lushan chubanshe.

Žižek, S. (1999). The ticklish subject: The absent centre of political ontology. London, New York: Verso.

Publisher's Note Springer Nature remains neutral with regard to jurisdictional claims in published maps and institutional affiliations. 